\title{
EDEMA ANGIONEURÓTICO HEREDITÁRIO E EPILEPSIA TIPO VISCERAL
}

\author{
ANNELise Strauss * \\ ANTONIO B. LEFÈVRE ** \\ FÁbIO PILEGGI ***
}

\begin{abstract}
O edema angioneurótico hereditário é caracterizado, clìnicamente, por crises repetidas de edema não inflamatório, circunscrito, atingindo preferencialmente face e membros, vias aéreas superiores e parede intestinal, determinando tumefação local, dificuldade respiratória e cólicas abdominais. É transmitido como fator autosomal dominante, podendo atingir várias gerações sucessivas.
\end{abstract}

O diagnóstico baseia-se na comprovação laboratorial de uma anomalia serológica hereditária caracterizada por carência do inibidor de C'1-esterase, assinalada por Donaldson e Evans ${ }^{5}$, em 1963, em pacientes com edema angioneurótico hereditário e seus familiares. A ausência do inibidor da C'1-esterase ${ }^{5}$, a diminuição de C'2, substrato fisiológico da C'1-esterase ativada ${ }^{2,6}$ e a diminuição do complemento total $\left(\mathrm{C}^{\prime} \mathrm{H} 50\right)^{3,6}$, permitem o diagnóstico diferencial em relação a entidades clínicas semelhantes, mas de etiologia distinta como, por exemplo, o edema angioneurótico não hereditário alérgico e cólicas abdominais de etiologia diversa.

Relataremos um caso que se distingue por apresentar alterações neurológicas esporádicas acompanhando o quadro clássico e cujo diagnóstico preciso foi estabelecido mediante dosagem do complemento sérico.

\section{OBSERVAÇAO}

I. F., 10 anos, sexo feminino, branca (Registro H.C. 835.549), atendida no Pronto Socorro Pediátrico em janeiro de 1967, sendo internada para estudo.

História pregressa da moléstia atual - Desde os 3 anos a paciente apresenta mensalmente e, ùltimamente, semanalmente, cólicas periumbelicaís violentas, precedidas por sonolência, vômitos e repuxamento labial. No início a dor é fraca e vai se intensificando no decorrer de algumas noras, sendo geralmente acompanhada

Da Faculdade de Medicina da Universidade de São Paulo: * Assistente do Serviço de Alergia (Dr. E. Mendes) da 1.a Clinica Médica (Prof. A. Ulhôa Cintra); $*$ Chefe de Disciplina de Neuropediatria, Livre-Docente da Clínica Neurológica (Prof. A. Tolosa); *** Assistente de Clínica Pediátrica (Prof. E. Marcondes). 
por palidez e vômitos. As cólicas desaparecem espontaneamente após algumas horas, sendo seguidas por prostração, cianose labial e sono profundo durante 3-4 horas. Estas crises, ocorrendo tanto de dia como de noite durante o sono e nunca tendo sido beneficiadas por medicação antiespasmódica, foram consideradas como epilepsia. Além disso, a paciente desde os 5 anos de idade apresenta mensalmente e, às vêzes, mais freqüentemente, episódios de edema frio, pálido, com localização variáveil nos membros superiores (dedos, mãos e antebraços) e inferiores (pés e pernas), acompanhado de formigamento e prurido local. Ás vêzes concomitantemente ocorrem cólicas abdominais, vômitos e dificuldade respiratória. $O$ edema tende a regredir espontaneamente após um a dois dias. A paciente não relaciona qualquer fator ao aparecimento dos diversos sintomas. Antecedentes pessoais - Gestação e parto normais. Apendicectomia há um ano, constituindo tentativa de resolver o quadro abdominal, sem qualquer benefício. Antecedentes familiares - O pai apresentou, dos 23 aos 25 anos de idade, inchaço periódico das māos, quando trabalhava em serviço pesado na lavoura; na mesma época, sofreu de cólicas abdominais violentas, não havendo, porém, coincidência dos sintomas; êste quadro regrediu espontaneamente. Uma irmã de 12 anos sofre de urticária e já teve diversos "desmaios", com 5-10 minutos de duração, sempre precedidos por anorexia durante 1-2 dias; numa ocasião apresentou, concomitantemente, cólicas abdominais passageiras. Exame fisico - Altura $1,09 \mathrm{~m}$. Pêso $23 \mathrm{~kg}$. Pele: intenso edema frio, não depressível, indolor na mão e antebraço direitos (Fig. 1). Amigdalas hiperemiadas,, com criptas purulentas. Aparelhos circulatório e respiratório aparentemente sem anormalidades: fígado palpável a um dedo do rebordo costal. Baço nāo palpável.

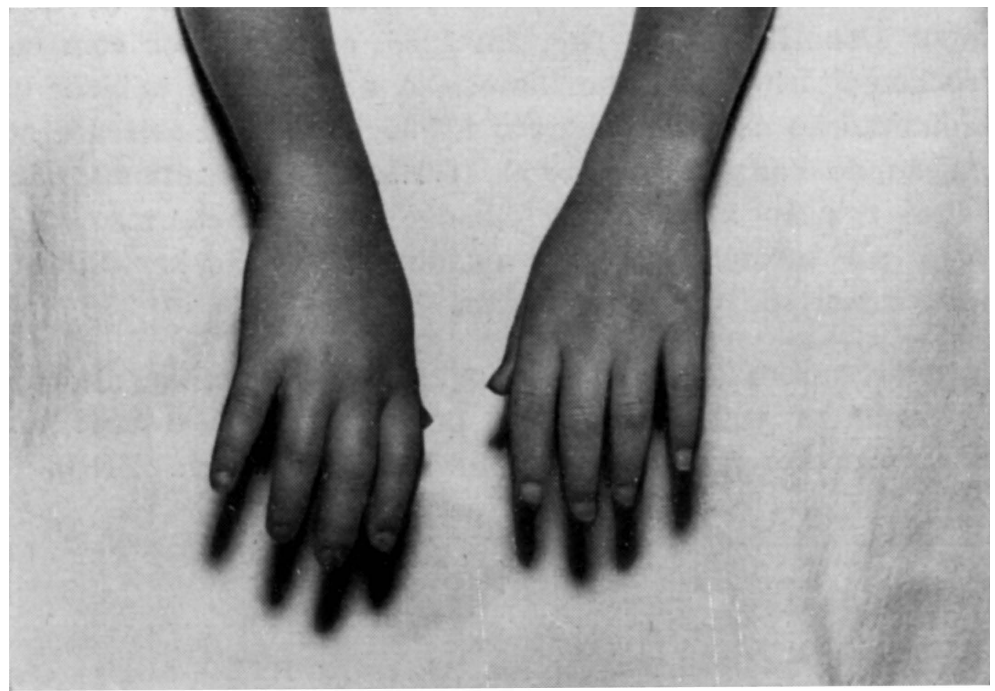

Fig. 1 - Caso I.F. Edema angioneurótico hereditário. Fotografia obtida em 11-5-1967, na mesma ocasião em que foi feito o EEG da figura 2.

Exames de laboratório - Hemograma - Leucócitos 10.800 (bastonetes 12; segmentados 60; eosinófilos 3; linfócitos 24; monócitos 1\%). Hemoglobina $13,7 \mathrm{~g}$. Velocidade de hemossedimentação $8 \mathrm{~mm}$ (N 12). Reação de Mantoux negativa. Prova de falcização negativa Dosagem de uréia no sangue $30 \mathrm{mg} / 100 \mathrm{ml}$. Amilase no sangue $376 \mathrm{U}$. 
Titulação do complemento sérico * (técnica de Wadsworth, Maltamer e Maltamer ${ }^{11}$ ) - Como padrões foram adotados os valores normais de Fava e col. ", considerando ainda dentro da normalidade, valores acima de abaixo de $100 \mathrm{U}$, seguindo a orientação dos mesmos autores. Os valores normais, médios e respectivos desvios padrōes, obtidos por Fava e col. ', mediante determinação em unidades 50\% de hemólise são: no homem 294,55 U/ml $\pm 13,34$; na mulher 234,74 $\mathrm{U} / \mathrm{ml} \pm 10,25$; no recém-nascido $174,84 \mathrm{U} / \mathrm{ml} \pm 12,53$. No caso aqui relatado foram obtidos os seguintes valores: em 12-5-1967, durante crise de edema angioneurótico, menor que 3,3 U (50\% de hemólise/ml sôro); em 24-5-1967, ocasiāo em que a paciente estava normal, $133 \mathrm{U}(50 \%$ de hemólise $/ \mathrm{ml}$ sôro).

Eletrencefalogramas - Foram feitos três exames: um em 14-4-1967, ocasião em que a paciente nada apresentava e que resultou normal para a idade; 0 segundo em 17-4-1967, ocasião em que a paciente estava com cólica abdominal, mostrou disritmia paroxistica na região temporal esquerda com grupos de ondas teta de voltagem elevada; o terceiro em 11-5-1967, durante crise de edema angioneurótico, mostrou disritmia paroxística na região temporal esquerda, com grupos de ondas teta de voltagem elevada (Fig. 2).

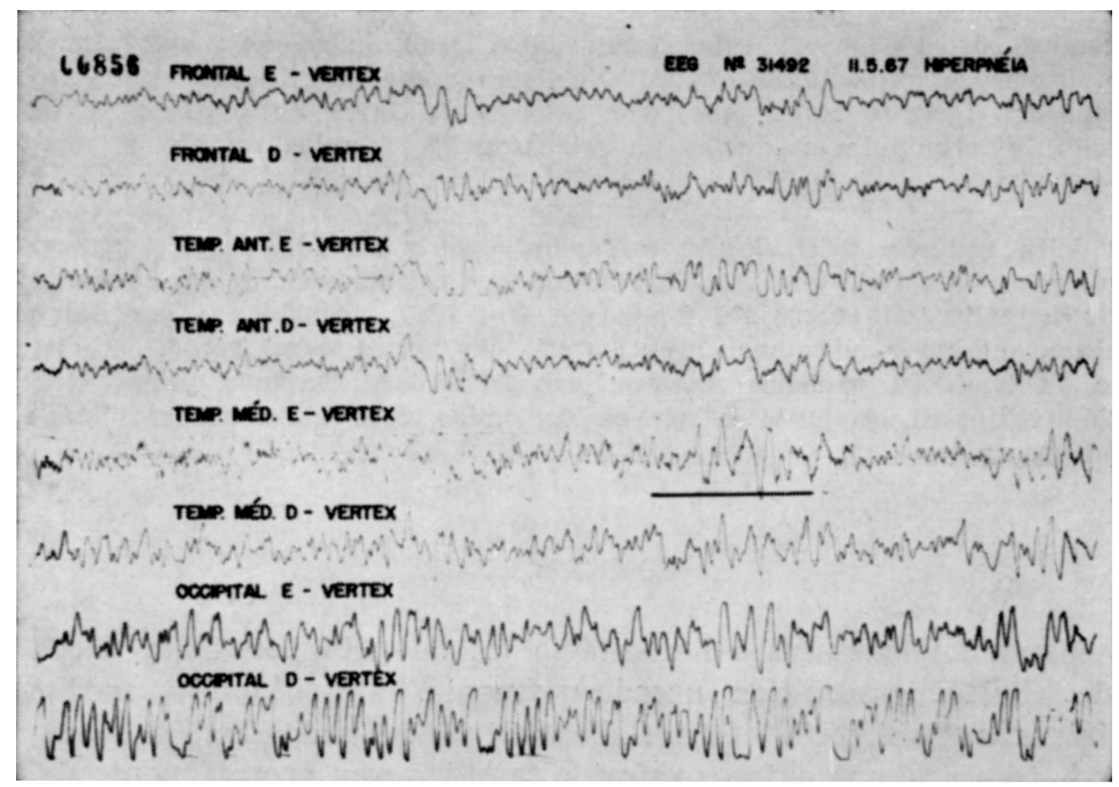

Fig. 2 - Caso I.F. Eletrencefalograma feito em 11-5-196\%, quando a paciente apresentava uma crise de edema angioneurótico.

Evolução - Depois de internada a paciente continuou a apresentar fortes cólicas abdominais e/ou edema dos membros (Gráfico 1). Considerando os caracteres das crises abdominais foi feita medicação anti-epiléptica (Comital, 1 comprimido cada 12 horas), sem melhora nitida. Aumentando, porém, a dose para $1 \frac{1 / 2}{2}$

* Nota dos autores - Agradecemos ao Prof. Celeste Fava Neto, chefe da Secçāo de Sorologia do Departamento de Microbiologia e Imunologia (Prof. C. da Silva Lacaz), pelas dosagens do complemento. 


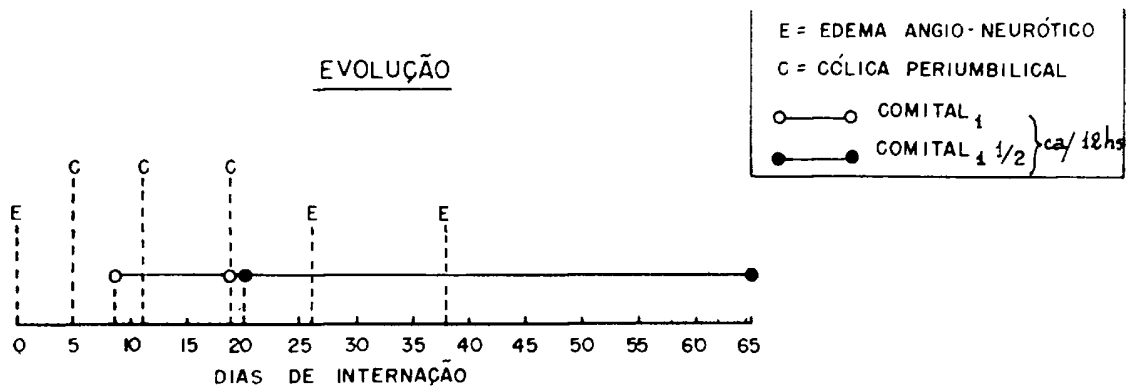

Gráfico 1 - Caso I.F. Evolução durante os 65 dias de internacão $e$ melhora obtida mediante a administração de doses adequadas de medicamento anti-epiléptico.

comprimidos cada 12 horas, houve completo desaparecimento de tôda a sintomatologia. Depois da alta hospitalar a paciente vem sendo acompanhada irregularmente no Ambulatório da Clínica Neurológica, tendo sido atendida, pela última vez, em dezembro de 1967. Até esta data foram assinalados dois episódios de crise visceral, ocorridos em setembro e outubro, não acompanhados de edema localizado nos membros. Deve-se notar que, por ocasião da crise de outubro, a medicação havia sido interrompida; na crise de setembro há dúvidas quanto à regularidade do tratamento.

Foi feita também a titulagem de complemento em familiares, com os seguintes resultados: no pai, que não apresenta qualquer sintoma há 10 anos, $238 \mathrm{U}$ (50\% de hemólise/ml sôro); na irmã, em 26-6-1967, ocasião em que também não apresentava qualquer sintomas, $187 \mathrm{U}\left(50 \frac{1}{2}\right.$ de hemólise $/ \mathrm{ml}$ sôro). O eletrencefalograma da irmā da paciente mostrou, em 26-6-1967, disritmia paroxística frustra na região temporal esquerda e grupos de ondas teta mais numerosas na região temporal esquerda.

\section{COMENTARIOS}

O edema angioneurótico hereditário foi descrito por Osler (1888) como entidade clínica transmitida hereditàriamente. Desde então, mediante dados clínicos e "pedigrees" foram diagnosticados mais de 500 casos em 61 famílias ${ }^{3}$, tendo alguns autores referido famílias com acometimento de $\mathbf{5}$ gerações sucessivas ${ }^{6}$. Em 1963, Donaldson e Evans ${ }^{5}$ demonstraram, em pacientes com edema angioneurótico hereditário, deficiência genética do inibidor do primeiro componente do complemento, C'1-esterase, que é uma $\alpha_{2}$-globulina especifica. Desde então a comprovação laboratorial desta anomalia sérica levou Donaldson e Rosen ${ }^{6}$ ao diagnóstico de mais de 100 casos novos em 3 anos, tendo Arnoldsson e col. 1 identificado a doença em 17 membros de uma família sueca. Mediante titulação do complemento sérico total conseguimos identificar uma família brasileira com pai e duas filhas atingidos.

No quadro clínico da nossa paciente ressalta a gravidade e freqüência das cólicas abdominais, precedidas e acompanhadas por vômitos e grande abatimento com sofrimento do estado geral. Os sintomas gastro-intestinais 
impõem o diagnóstico diferencial cuidadoso, pois as intervenções cirúrgicas, visando resolver o quadro clínico, quando não prejudiciais, são inúteis, como ocorreu no nosso caso e em outros referidos por Arnoldsson e cl. 1, cujos pacientes, submetidos à laparotomia exploradora, apresentavam edema da parede intestinal e líquido claro na cavidade abdominal.

As dificuldades respiratórias e a cianose apresentados pela paciente constituem sintomas de prognóstico grave: óbito por edema de glote tem ocorrido em 6 a $54 \%$ dos casos, conforme os diferentes autores ${ }^{3}$. Donaldson e Rosen ${ }^{6}$ observaram 6 óbitos súbitos em 3 gerações de uma única familia. Contrasta a gravidade do edema angioneurótico hereditário, resistente à terapêutica com antihistamínicos, corticosteróides e adrenérgicos ${ }^{2}$, com a benignidade do edema angioneurótico não hereditário, de etiologia diversa.

De interêsse especial é o quadro neurológico apresentado pela paciente, caracterizado por crises focais com repuxamento da comissura labial e alterações eletrencefalográficas transitórias durante as crises desencadeadas, presumivelmente, por edema cerebral. Considerando êstes dados, assim como os demais sintomas, principalmente as cólicas abdominais acompanhadas de sofrimento e grande abatimento do estado geral, foi feito inicialmente o diagnóstico de epilepsia visceral. Este diagnóstico parece também justificado considerando-se que houve desaparecimento de tôda sintomatologia neurológica, abdominal, cutânea e respiratória após instituição de medicação anticonvulsiva, em dose adequada, utilizando uma associação de prominal com difenilidantoinato de sódio, especialmente indicada para casos de epilepsia visceral. Esta observação é de grande interêsse teórico e prático, necessitando ser confirmada em outros casos.

O conceito de epilepsia autonômica, bem estabelecido por Lennox ${ }^{8}$, inclui diversas manifestações paroxísticas e recurrentes; segundo êste autor, não é suficiente saber que sintomas neurovegetativos são manifestações muito importantes que podem acompanhar crises de grande mal. Deve-se reconhecer que "uma hiperatividade paroxística de nervos que suprem vísceras, glândulas de secreção interna e artérias, podem ter origem central e significar plenamente epilepsia". As mais freqüentes formas de crises autonômicas são as constituídas por dores abdominais, taquicardia ou bradicardia, palidez, rubor, sudorese, salivação, vômitos, hipertermia, cefaléia ( tipo enxaqueca), hipertensão arterial, enfim, numerosos efeitos desta "hiperatividade paroxística de nervos". Lennox não refere o edema localizado como manifestação de epilepsia autonômica.

Embora a etiopatogenia do edema angioneurótico hereditário constitua assunto ainda controvertido, haveria talvez um fator regulador neurológico, responsável pela natureza esporádica das manifestações de angiedema. $\mathrm{O}$ papel do sistema nervoso no desencadeamento das crises foi também lembrado por Donaldson e Rosen ${ }^{6}$, observando um caso de edema angioneurótico hereditário, com manifestações localizadas em um lado do corpo, em paciente com atrofia de hemisfério cerebral. 
Até o presente o estudo do sistema do complemento sérico constitui o método mais direto e eficiente para o diagnóstico do edema angioneurótico hereditário, possibilitando a identificação precoce dos casos 4, 9, 10, constatando-se, por métodos imunoquímicos e bioquímicos, ausência do fator inibidor de C'1-esterase ${ }^{5}$ e diminuição do substrato fisiológico de C'1 ativado, isto é, de $\mathrm{C}^{\prime} 2^{3}$. A titulação do complemento total (C'H50) por técnica de execução relativamente fácil, não necessitando de reativos especiais, foi utilizada no nosso caso e refletiu nìtidamente a diminuição de $\mathrm{C}^{\prime} 2$, observação já feita por outros ${ }^{5}$, que evidenciaram ausência quase total do complemento durante as crises e título inferior ao normal em intervalos assintomáticos.

\section{RESUMO}

É relatado um caso de edema angioneurótico hereditário que, além de sintomas cutâneos, gastro-intestinais e respiratórios, apresentava sintomatologia neurológica com quadro de epilepsia visceral, além de crises convulsivas focais faciais e durante as crises, alterações eletrencefalográficas focais.

A dosagem do complemento total ( $\left.\mathrm{C}^{\prime} \mathrm{H} 50\right)$ permitiu o diagnóstico de edema angioneurótico hereditário, tendo sido feito tambẻm o diagnóstico de epilepsia visceral, levando em conta não só a sintomatologia, como o resultado dos eletrencefalogramas e a prova terapêutica.

O desaparecimento de tôda a sintomatologia após medicação anticonvulsiva constitui dado interessante, merecendo ser investigado em outros casos. Considerando a semelhança clínica da cólica abdominal produzida por epilepsia visceral e por edema angioneurótico hereditário, bem como a coexistência, no caso apresentado, de edema angioneurótico hereditário e epilepsia visceral, fica ressaltada a importância de futuras investigações clínico-laboratoriais, visando estabelecer possivel relação etiológica entre estas entidades clínicas.

\section{SUMMARY}

\section{Hereditary angioneurotic oedema and visceral epilepsy}

A case of familiar angioneurotic oedema is reported in which, besides the cutaneous, gastro-intestinal and respiratory symptoms, there were neurological manifestations of visceral epilepsy and focal facial seizures, with localized eletroencephalographic alterations.

Dosage of total complement (C'H50) establised the diagnosis of familiar angioneurotic oedema. However, considering clinical manifestations, EEG records and therapeutic results the diagnosis of visceral epilepsy seems also justified. Disappearance of all symptoms with anticonvulsive medication in adequate dosage is of special interest and should be investigated in other cases. 
Considering the clinical similarity of abdominal pain due to visceral epilepsy and to angioneurotic oedema, as well as the simultaneous occurrence in the reported case of angioneurotic hereditary oedema and abdominal epilepsy, further research is suggested in order to establish a possible relationship between these two entities.

\section{REFERENCIAS}

1. ARNOLDSSON, H.; BELIN, L.; HALLBERG, L.; HELANDER, E.; LINDHOLM, B. \& WESTLING, H. - Hereditary periodic edema. Acta Med. Scandinav. 181:115, 1965. Resumo in J. Allergy 34:11, 1967.

2. AUSTEN, F. - Familial nonallergic angioneurotic edema (C'1 esterase inhibitor deficiency). Arch. Dermatol. 92:1947, 1965.

3. AUSTEN, K. F. \& SHEFFER, A. L. - Detection of hereditary angioneurotic edema by demonstration of a reduction in the second component of complement. New Engl. J. Med. 272:649, 1965.

4. Complement - Ciba Foundation Symposium. Edit. G. E. V. Wolstenholme \& J. Knight. J. \& A. Churchill Ltd., London, 1965.

5. DONALDSON, V. H. \& EVANS, R R. - A biochemical abnormality in hereditary angioneurotic edema: absence of serum inhibitor of C'1-esterase. Amer. J. Med. 35:37, 1963.

6. DONALDSON, V. H. \& ROSEN, F. S. - Hereditary angioneurotic edema: a clinical survey. Pediatries 37:1017, 1966.

7. FAVA NETTO, C.; MANISSADJIAN, A.; ARMINANTE, H. O. P.; CORRADINI, H. B. \& RUIZ Jr., G. - O complemento do sôro humano em indivíduos normais. Rev. Inst. Med. Trop. São Paulo 8:37, 1966

8. LENNOX, W. G. - Epilepsy and Related Disorders. Little, Brown \& Co., Boston, 1960 .

9. MELMON, K. L. \& CLINE, M. J. - Interaction of plasmakinins and granulocytes. Nature 213:90, 1967.

10. RAPP, H. J. \& BORSOS, T. - Complement research. Fundamental and applied. J.A.M.A. $198: 1347,1966$

11. WADSWORTH, A. B. - Standart Methods of the Division of Laboratories and Research of the New York State Dept. of Health. William and Wilkins Co., Baltimore, 1949.

Serviço de Alergia - Faculdade de Medicina da Universidade de São Paulo São Paulo, SP - Brasil. 